\title{
LA MODESTIA, REVISITADA
}

Beatriz Quintanilla Madero

\section{RESUMEN}

Revisitar no es un verbo utilizado frecuentemente en castellano. Sin embargo, evoca rápidamente un concepto de "volver a", "regresar a un lugar que previamente había visitado ya" y, por lo tanto, tenemos sobre él algunos recuerdos. Revisitar es una palabra que he tomado prestada del inglés para conseguir, a través de ella, volver a un lugar, un concepto, quizá un poco olvidado o borrado por el paso del tiempo.

La modestia, por su parte, es una palabra que no está de moda. El pudor, mucho menos. ¿Son conceptos sin ningún significado actual? ¿Son vocablos que sólo pueden utilizarse para hacer referencia a realidades pasadas de moda? Por eso, he puesto de intento en el título "revisitar". Volver a un lugar que conocemos, o que hemos conocido, pero que tal vez ha cambiado, y siento curiosidad de saber si sigue igual, en el mismo sitio, si mi recuerdo es exacto o si, con el paso de los años, aquel recuerdo, al contrastarlo con el presente, ya no tiene nada que ver con el que tenía: aquella casa que nos parecía inmensa, en realidad es una casita, y la "cueva" donde se escondían los "ladrones", no pasa de ser una pequeña hendidura en la pared del jardín.

Revisitar un concepto que no está de moda y que ha disminuido en popularidad, puede ser una tarea incómoda e ingrata. Incómoda, en primer lugar, para quien se echa encima la tarea, a riesgo de parecer que es old fashioned" o que está viviendo en 
otro mundo. Sin embargo, en mi trabajo como psiquiatra, me enfrento diariamente a muchas personas de todas las edades que, al ser cuestionadas a fondo sobre lo que piensan de la vida, de los problemas actuales, de lo que les sucede a ellas mismas, no están tan seguras de que estos temas estén pasados de moda y no saben cómo afrontarlos.

Por eso me ha parecido importante que, en una revista universitaria, dedicada de modo especial a los pedagogos -quienes tienen la importante tarea de formar a las personas-, tratemos el tema de la modestia, el pudor, la intimidad y, al revisitar estos conceptos, discernamos qué podemos rescatar de aquellas visitas realizadas algún día y de las que, quizá, sólo quedaron recuerdos vagos y poco nítidos.

\section{EL CUERPO QUE SOY YO}

Cuando hablamos de este tema es importante saber primero por qué es necesario pensar en esto: por qué los seres humanos pensamos sobre la pureza como virtud, y sobre el pudor y la modestia que forman parte de ella.

Nos damos cuenta de que pensamos en ella, y en otras virtudes, porque podemos reflexionar. Los animales no reflexionan y ni se cuestionan si lo que hacen está bien o está mal; simplemente actúan.

Los seres humanos, además de actuar, sabemos que somos nosotros mismos los que actuamos y que lo que realizamos lo estamos haciendo nosotros mismos, no otra persona.

Nos damos cuenta que cuando realizamos algo, aunque lo hagamos con una parte de nuestro cuerpo, somos nosotros mismos, completos, la persona toda entera, yo mismo, el que ha llevado a cabo la acción y no sólo una parte de nosotros. Por ejemplo: digo, "Yo escribí una carta"; no digo: "Mi mano escribió una carta". Somos una unidad entera de alma y cuerpo, de cuerpo y espíritu que es y funciona como un todo. No somos partes separadas. No pensamos en nosotros mismos como en una tercera persona; no se nos ocurre decir: "Voy a 
ver a la enfermedad de María", sino que decimos: "Voy a visitar a María que está enferma". No comento: "A mi cabeza le cortaron el cabello", sino "Me corté el cabello", o "Me cortaron el cabello $a \mathrm{mi}$.

Es decir, no tenemos un cuerpo separado de nosotros mismos, sino que el cuerpo yo “lo soy”. Cuando pienso en mí, cuando cada uno de nosotros piensa en sí mismo, nos pensamos con un cuerpo, con una figura, con una imagen corporal concreta. Este cuerpo tiene unas características físicas: altura, volumen, peso, color de ojos, color de pelo... es el cuerpo de un hombre o de una mujer que soy yo.

Todas nuestras acciones, todas nuestras relaciones, el contacto con las demás personas es a través de nuestro cuerpo. Y no da lo mismo cómo utilizamos o cómo tratamos ese cuerpo, ya que forma parte de nuestra propia persona ${ }^{1}$.

\section{CAPACIDAD DE PENSAR Y DE REFLEXIONAR}

Pero el cuerpo no es sólo un cuerpo físico. Nuestro cuerpo es un cuerpo vivo. No somos seres inertes. Somos seres vivos y estar vivo significa que llevamos a cabo las acciones que implican vivir. Desde un punto de vista biológico, tenemos una serie de facultades que nos permiten llevar a cabo los procesos fisiológicos para sobrevivir. Tenemos, al igual que cualquier ser vivo, la facultad de crecer, desarrollarnos, reproducirnos y finalmente morirnos. Todo ser vivo tiene la facultad de nacer, crecer, reproducirse y morir. Los animales, además de estas funciones elementales que se llaman vegetativas porque también las tienen las plantas, presentan otras tres facultades o funciones: la facultad motora, que sirve para moverse, para ir de un lado a otro; la facultad de conocer lo inmediato a través de los sentidos internos y externos, y la

${ }^{1}$ Cfr. Yepes Stork R.; Aranguren Echeverría J., Fundamentos de Antropología. Un ideal de la excelencia humana., Caps.1-3, pp.9-80. 
facultad de apetecer, de desear lo que los sentidos nos presentan. Por eso podemos observar cómo los animales -sobre todo animales superiores, como el perro- conocen a sus dueños y apetecen bienes sensibles como la comida.

Algunos animales superiores y los seres humanos, además tenemos la afectividad. La capacidad de poseer sentimientos. En la afectividad residen las emociones, pasiones y sentimientos. Hay emociones que están completamente determinadas por un correlato fisiológico, por ejemplo sentir placer al comer algo que me gusta; hay otros sentimientos que no tienen nada que ver con algo físico y son resultado de un conocimiento o de un deseo intelectual: por ejemplo, tener ilusión de conseguir un trabajo, sentir satisfacción al recordar que me salió bien un negocio, o sentir tristeza porque he tenido un fracaso. El amor, por ejemplo, es un sentimiento hacia una persona a la que conozco y que quiero, y lo siento cuando estoy con esa persona. Pero también es un sentimiento que puedo hacer crecer con la imaginación o con el conocimiento intelectual sin que esté presente junto a mí la persona amada. El amor a Dios, es un sentimiento superior, pero reside en la afectividad. La fidelidad a alguien que en ese momento está ausente, o que con el pasar del tiempo ha perdido algunas características físicas que me atraían y que tenía cuando le conocí ${ }^{2}$.

El ser humano, que es unidad de cuerpo y espíritu, posee todas las cualidades que tiene cualquier ser vivo: facultades vegetativas, las sensitivas y la afectividad. Pero además, posee las facultades espirituales que también se llaman racionales y que son la inteligencia y la voluntad. El ser humano posee un alma espiritual. Tener un alma espiritual significa que poseemos unas facultades espirituales o funciones racionales o intelectivas que son la inteligencia y la voluntad. A través de la inteligencia, cuyas principales funciones son el pensamiento $y$ el lenguaje, adquirimos un conocimiento intelectual, superior

${ }^{2}$ Cfr. Quintanilla Madero, B., Apuntes de Psicología Médica. 
al conocimiento sensible. A través de la voluntad somos capaces de dirigir nuestra conducta de un modo racional. Las funciones intelectuales nos permiten conocer y decidir lo que queremos sin que nuestra conducta esté determinada de modo definitivo por el instinto o la necesidad como en el animal. De este modo somos capaces de conocer algo y de decidir si queremos o no poseer ese algo o actuar de un modo o de otro. No estamos necesariamente determinados. Por ejemplo, podemos decidir si queremos comer o no, aunque tengamos hambre. Podemos decidir ayudar a alguien aunque no nos caiga bien. Es decir, lo corporal en el ser humano no determina de modo completo y definitivo nuestra conducta. Tenemos libertad para decidir lo que queremos ${ }^{3}$.

Pero, además, la inteligencia nos capacita para poder pensar sobre lo que conocemos, sobre lo que pensamos, sobre lo que vivenciamos. Todo lo que vivimos se nos va quedando "dentro", tenemos una interioridad sobre la que podemos reflexionar y conocer que reflexionamos.

\section{LA INTIMIDAD}

Mientras que los animales son capaces de tener una cierta interioridad, porque pueden recordar, tienen memoria e imaginación, los seres humanos no solamente tenemos una interioridad, sino que tenemos intimidad; es decir, conocemos nuestra interioridad y muchas de nuestras acciones son inmanentes: se quedan dentro de nosotros mismos. Esta intimidad, este mundo interior que podemos conocer, es lo más "nuestro" que tenemos. Forma parte de nuestra identidad, del yo más profundo y personal que es propiamente mío.

En mi relación con los demás, sólo comparto mi intimidad con aquellas personas que son mis amigas, a las que les doy

${ }^{3}$ Cfr. Burggraf J., "Bases de la Medicina: Antropología Cristiana", en Medicina

Pastoral., pp.34-62. 
el derecho de "entrar" en aquella parte de mí que es más personal y que no quiero que esté al aire. Es un área restringida a la que sólo doy acceso a quien yo quiero, y sólo me entrego a quien yo quiero. Cuando nos damos a nosotros mismos, lo que damos a otros es parte de nosotros mismos, parte de esa intimidad. Podemos entregar parte de nosotros en diferentes niveles, pero esa intimidad es lo que consideramos el núcleo, nuestro yo personal.

Al ser el hombre una unidad de alma y cuerpo ${ }^{4}$, esa interioridad forma parte de mi persona completa y la reconozco como mía, formando parte de toda mi persona. En esa interioridad, en esa intimidad, se van acumulando los recuerdos, imágenes, pensamientos y reflexiones que he formado, el modo de ver la vida, mis ilusiones y deseos, los sentimientos y los amores. Lo que más quiero, lo guardo en mi intimidad, de la que también forma parte el corazón. Todo esto que tengo dentro, redunda en mí directamente, es decir, se queda en mí, pero también sale de mí y se expresa en mi conducta. Lo que yo hago, el modo como trato a los demás, como me trato a mí mismo, las metas que tengo, el proyecto de vida que he ideado se expresa en mis acciones y en toda mi persona; lo comunico a los demás a través del lenguaje. Por eso, los demás pueden conocernos, porque podemos expresar lo que somos, lo que queremos y lo que nos pasa.

La intimidad la tengo al resguardo de los demás con un sentimiento natural que se llama pudor. El pudor es el sentimiento que me enseña a proteger mi intimidad. Es un sentimiento natural porque lo tenemos desde que nacemos. Podemos observar cómo los niños son pudorosos ya desde pequeños. El pudor lo experimentamos en muchos campos: no le cuento a cualquiera mis cosas, no dejo que cualquiera me vea cuando me estoy cambiando de ropa. No hago partícipe a cualquier

${ }^{4}$ Cfr. Quintanilla Madero, B., Personalidad madura: Temperamento y Carácter., pp.112-117. 
extraño de mis problemas. La barrera natural de esta intimidad es mi propio cuerpo; mi cuerpo delimita mi yo del resto de las personas y de las cosas. Pero mi cuerpo no es algo diferente de mi persona. Yo, el cuerpo lo soy y lo trato con respeto como consecuencia de que no es algo añadido a mí. Por eso hay acciones que son íntimas y las llevo a cabo a solas, por ejemplo: bañarse, ir al baño, arreglarse, vestirse. Trato mi cuerpo con respeto, y hago que mi cuerpo lo respeten los demás. A nadie, en su sano juicio, se le ocurre bañarse en una fuente pública, o dejar abierta la puerta de la casa cuando voy al baño para que entre cualquiera. Todos tenemos un mundo íntimo que resguardamos de las miradas de los extraños. De esta necesidad de intimidad y de resguardar nuestra propia vida, surge la exigencia de tener algo propio en donde no tienen acceso los demás. Por eso tenemos una casa, una ropa que usamos, unos bienes materiales que consideramos nuestros y que no permitimos que cualquiera tenga acceso a ellos. Incluso dentro de la propia casa, guardamos lo que consideramos más íntimo de una manera especial: las cartas de nuestros amigos, un diario, el recuerdo de una ocasión especial...

Nuestro cuerpo es uno de esos bienes personales que debemos resguardar. No podemos dar libre acceso a cualquiera. El cuerpo es parte de nuestra persona y sólo entregamos nuestra persona a quien nos da la gana, no a cualquiera. Por eso lo cuidamos y lo respetamos, y una manifestación de ese respeto por nuestro cuerpo es el pudor y la modestia en nuestra conducta, y en el modo de tratar y presentar nuestro cuerpo ante los demás, que en definitiva es el modo de tratarnos y de presentarnos a nosotros mismos.

El pudor no puede depender por tanto de la moda. No tengo por qué enseñar mi cuerpo a cualquiera, así como no cuento a cualquiera lo que me pasa. Todos tenemos experiencia de intimidad y de lo que es mío y, por lo tanto, privado. Si yo ahora expusiera una clase y me acercara a cualquier 
persona y leyera las notas que está tomando, podría decirme con toda razón que no tengo derecho a ver sus apuntes. Si un backer, o cualquier otra persona, descubre la clave de mi $\boldsymbol{e}$-mail y se mete a husmear, tengo la sensación de que alguien se ha metido en mi intimidad.

¿Por qué entonces no reconocemos con la misma facilidad la falta de pudor o la entrada en mi intimidad cuando nos referimos al cuerpo? A veces sucede que algunas conductas las consideramos como algo que no importa cómo se manifiestan. Dentro de estas conductas está la sexualidad y todo lo que se refiere a ella. La sexualidad forma parte también de toda nuestra persona, no es algo que podemos dar a cualquiera, ni en cualquier parte o situación, porque es parte de nosotros mismos.

\section{SEXUALIDAD E INSTINTO SEXUAL}

La sexualidad está integrada por muchos componentes, no sólo por el instinto sexual. Aunque los seres humanos podemos dirigir nuestra conducta a través de la inteligencia y la voluntad, el instinto es parte integrante de nuestra forma de ser. Es parte de nuestra materia prima. Cuando hacemos referencia a la sexualidad, nos referimos también a que nuestra persona es una persona femenina o masculina, y esto nos hace vivir la vida y entender nuestra existencia desde un modo de ser de hombre o de mujer. Queremos a nuestros padres como hombre o como mujer. Entendemos la vida como hombre o como mujer, es parte de nuestro ser.

A veces se piensa en la sexualidad como si ésta estuviera constituida únicamente por el instinto sexual, reduciendo la sexualidad sólo al instinto. Como si ser hombre o mujer se redujera sólo a la posibilidad de tener relaciones sexuales o de responder sexualmente a un instinto. Eso es reducir nuestra persona a la pura genitalidad. La sexualidad es algo mucho más amplio que forma parte de nuestra identidad personal y nos constituye de una manera completa, como una persona 
femenina o masculina. Por eso es importante entendernos como hombres o como mujeres completos. Pero hay que comprender que el instinto sexual es parte de nuestra sexualidad y que es parte de nuestra materia prima. Y hay que cuidarlo también como parte de nuestra intimidad.

El instinto sexual se comporta de diferente manera en el hombre que en la mujer, porque el hombre responde ante un impulso sexual de una forma mucho más rápida que la mujer y se excita también mucho más rápido. Las mujeres debemos conocer esa forma de reaccionar del hombre y de la mujer, porque puede pasar que lo que a nosotros nos parece "normal", que "no importa", en los hombres que nos observan y que nos rodean, provocan sensaciones que despiertan el instinto sexual.

El instinto sexual no es malo, es parte de nuestra naturaleza. "El instinto sexual, por su propia naturaleza -nos señala el Papa- sirve al bien más fundamental de la especie humana, que no es otro que la existencia misma de la especie. Es un instinto que busca transmitir la vida y de esto depende ese bien de la naturaleza humana" 5 .

"(...) Para los seres que no están dotados de razón, las leyes de la naturaleza son por sí mismas leyes de la existencia; para el hombre son, además, pistas para el pensamiento, temas que rigen la experiencia. Y esta experiencia, en su forma consciente, se obtiene a partir de la profundidad" ${ }^{6}$.

Es decir, no basta tener un mundo interior, una intimidad, hace falta hacerla crecer, profundizar en lo que pensamos, en lo que hacemos, en lo que vivimos. Es fácil hacer lo que todo mundo hace, pensar como todo mundo piensa. Reflexionar y actuar como uno cree que debe hacerlo es más difícil porque muchas veces hay que ir contra corriente.

${ }^{5}$ WOJTYLA., Karol., El don del amor., p.53.

${ }^{6}$ Ibid., p.54. 


\section{EL PUDOR: SENTIMIENTO Y EXIGENCIA NATURAL}

Vivir el pudor, la modestia, la pureza, nos puede parecer una exigencia difícil en el mundo actual, pero cuando pensamos por qué la vivimos y profundizamos en las razones, la exigencia se nos convierte en un modo de conducta personal.

No es la Iglesia la que pone las leyes a la naturaleza. No es la Iglesia la que me señala que le ponga una contraseña a mi e-mail: es el sentimiento natural de lo que es privado y es mío. No es la Iglesia la que afirma que ponga llave a mi casa, o alarma a mi coche. No es la Iglesia la que me marca que debo respetar los bienes ajenos, porque es consciente de que las personas tenemos derecho a tener unos bienes que son privados.

El pudor por tanto, no es una virtud que la Iglesia nos señale que hay que vivirla. Es una exigencia natural de la persona humana, sea hombre o mujer. El pudor no es una virtud para que la vivan sólo las mujeres; pero cuando la mujer deja de vivirla, se corrompe más fácilmente que el varón y, además, corrompe a los que la rodean.

El pudor y la modestia son parte de la virtud de la pureza. La pureza es aquella virtud que nos permite mantener pura e inviolable nuestra intimidad, empezando por el propio cuerpo. Nos permite guardar nuestra propia persona para entregarla, en caso de que ése sea nuestro camino, a aquella otra persona con la que queremos compartir la vida para siempre. O para guardarla para Dios.

La mujer debe ser consciente de que su valor personal se lo da el hecho de ser persona, una persona humana que tiene inteligencia y voluntad, que es además imagen de Dios. El valor no lo da la ropa que nos ponemos o las cosas que tenemos. El valor lo tenemos por el hecho de ser personas, imagen de Dios. Si somos imagen de Dios, hemos de comportarnos de acuerdo a eso $^{7}$.

Cfr. Juan Pablo II., Mulieris Dignitatem., pp.88-94. 
El modo de vestir es parte de nuestra persona, expresa nuestra intimidad, los valores que tenemos. Una mujer a quien no le importa llevar toda la ropa pegada, la "panza" de fuera, los pantalones "embarrados", transmite un mensaje: no el de que es una persona valiosa, que sabe lo que vale por sí misma, sino el de que es alguien que provoca miradas sólo a su cuerpo y no a su ser personal. Por eso es difícil que una mujer exija respeto si ella no lo tiene por sí misma.

¿Qué manifestaciones tiene el pudor? Tiene muchas y muy concretas. Por ejemplo: el modo de vestirnos, con ropa a la moda pero decente. No hace falta llevar la falda tan corta que a la hora de sentarse o agacharse se vea todo, o unos escotes que no dejan ya lugar a la imaginación, o que encienden el deseo sexual de quien nos mira. No hace falta llevar la blusa enseñando todo el abdomen o tan pegada que deja al descubierto todas las formas íntimas de la mujer. Es importante también cuidar el tipo de ropa interior que nos ponemos, no utilizar una ropa interior que refuerza las formas naturales y hace que se note todo mucho más. Se puede ir vestida elegante y a la moda sin ir provocativamente. Es duro oír de parte de un hombre que hay mujeres que van como mercancía, a ver qué venden. ¿Cómo pretende esa mujer que se le respete por lo que ella es, cuando ella misma se esfuerza en parecer otra cosa? Es fundamental pensar que no nos vestimos para provocar, sino para cuidar ese cuerpo que es parte de nosotras mismas y que cuidamos porque nos queremos y nos respetamos, a nosotras mismas en primer lugar.

El pudor también se vive en la propia casa. No hay que confundir la confianza, el estar en "familia" o entre amigas, con una falta de educación y de pudor. Los hermanos y los papás también tienen ojos, sentimientos e instintos, y es importante darnos cuenta de que podemos provocarlos sin querer. Por eso no puede uno pasearse por toda la casa en pijama, sin bata, en ropa interior, o a veces sin ropa porque 
estamos "entre mujeres". Es mejor cerrar la puerta cuando vamos al baño, aunque tengamos "mucha confianza" porque "estoy en mi casa". Se pueden usar trajes de baño muy bonitos y a la moda sin necesidad de enseñar todo. En algunos países es impresionante ver cómo las mujeres han perdido a tal grado la capacidad de sentir pudor que sólo se ponen una parte mínima para ir a nadar y dejan a descubierto el pecho.

Vivir el pudor no es mojigatería o cosa de gente anticuada. Es la actitud de alguien que se quiere y se respeta a sí misma y quiere que la respeten y la quieran igual. Es la actitud de alguien que sabe cuánto vale como persona y que sabe también cuánto valen los demás y por eso los respeta.

El pudor y la modestia también se deben cuidar en el noviazgo y en el matrimonio. El noviazgo es una época para conocer al otro, a la persona que amo y con la que quiero compartir mi vida. Pero en el noviazgo todavía no nos pertenecemos. Sólo pertenecemos con total derecho a la persona del otro cuando nos casamos. Por eso hay que esforzarse por vivir un noviazgo limpio; por vivir la pureza en la relación con el novio y el respeto mutuo.

Es difícil pero no imposible y un matrimonio constituido sobre el amor y el respeto a la otra persona se construye sobre bases sólidas. En el matrimonio también se ha de vivir la pureza que permite expresar ese respeto al otro y mantener la fidelidad toda la vida. 


\section{REFERENCIAS BIBLIOGRÁFICAS}

BURGRAFF, J., "Bases de la Medicina. Antropología Cristiana", en Medicina Pastoral., Monge M.A., Pamplona., EUNSA., 2002. JUAN PABLO II., Mulieris Dignitatem., La dignidad de la Mujer., Madrid., 1988.

QUinTanilla Madero, B., Apuntes de Psicología Médica., México., Edición experimental., 2003.

QUINTANILlA Madero, B., Personalidad Madura: Temperamento y Carácter., México., Investigación para la Docencia No.3., Universidad Panamericana., Publicaciones Cruz O, S.A., 2003. WOJTYLA, K., El don del amor., Madrid., Biblioteca Palabra., Escritos sobre la familia., 2aㅡ ed., Madrid., 2001.

YEPES Stork, R.; ARANGUREN Echevarría J., Fundamentos de Antropología. Un ideal de la excelencia humana., Pamplona., EUNSA., 4⿳亠丷a.ed., 1999. 